\title{
Risk factors for transposition of the great arteries in Saudi population
}

\author{
Abdulrabman Alfarhan, MBBS, Meshari Alquayt, MBBS, Mohammed Alshalhoub, MBBS, \\ Muhannad A. Alnahdi, MBBS, Emad Masuadi, PhD, Fahad Alhabshan, MD, FESC.
}

\begin{abstract}
الأهداف : لتقييم عوامل الخطر الختملة وتأثيرها على تطور تبديل الشرايين

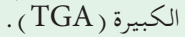

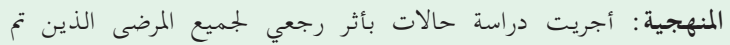

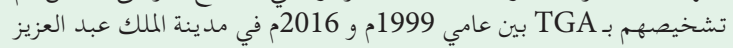

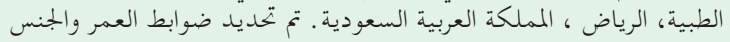

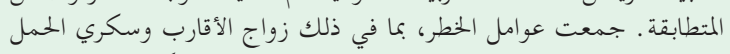

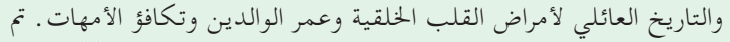

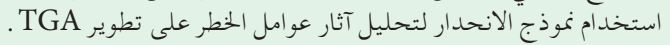

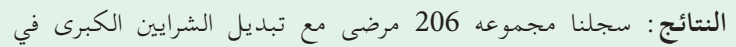

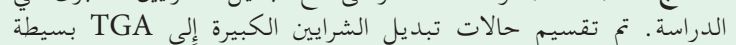

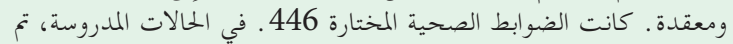

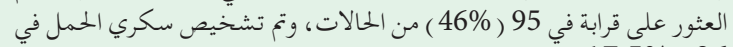

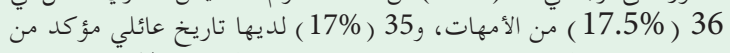

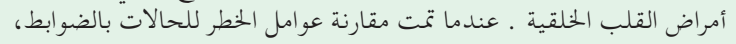

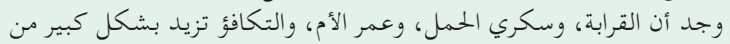

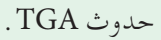

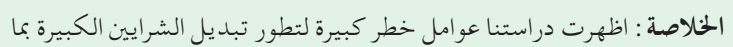

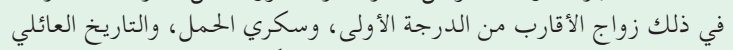

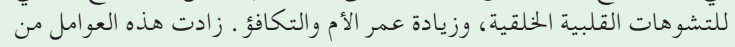$$
\text { الخطر بمقدار ضعفين على الأقل . لماتل }
$$

Objectives: To assess potential risk factors and their effect on the development of transposition of the great arteries (TGA).

Methods: A retrospective case-control study of all patients diagnosed with TGA between 1999 to 2016 at King Abdulaziz Medical City, Riyadh, Saudi Arabia. Age and gender-matched controls were selected. Risk factors, including consanguinity, gestational diabetes, family history of congenital heart disease, parental age, and maternal parity, were collected. Regression modeling was used to analyze the effects of risk factors on the development of TGA.

Results: A total of 206 patients with transposition of the great arteries were enrolled in the study. Transposition of the great arteries cases were divided into simple and complex TGA. Selected healthy controls were 446. In the studied cases, consanguinity was found in $95(46 \%)$ of cases, gestational diabetes was diagnosed in $36(17.5 \%)$ mothers, and $35(17 \%)$ had a confirmed family history of congenital heart disease. When risk factors of the cases were compared to the controls, consanguinity, gestational diabetes, maternal age, and parity were found to significantly increase the incidence of TGA.

Conclusion: Our study revealed significant risk factors for the development of transposition of great arteries including first degree consanguineous marriages, gestational diabetes, family history of congenital cardiac anomalies, and increasing maternal age and parity. These factors increased the risk by at least 2 folds.

Keywords: transposition of the great arteries, consanguinity, gestational diabetes, family history, paternal age, maternal parity

Saudi Med J 2020; Vol. 41 (10): $1054-1062$ doi: 10.15537/smj.2020.10.25418

From the Department of Cardiac Sciences, Ministry of National Guard Health Affairs, Riyadh, Kingdom of Saudi Arabia.

Received 29th July 2020. Accepted 13th September 2020.

Address correspondence and reprint request to: Dr. Fahad Alhabshan, Associate Professor, Cardiac Sciences, College of Medicine, King Saud bin Abdulaziz University for Health Sciences, Riyadh, Kingdom of Saudi Arabia. E-mail address: habshanf@ngha.med.sa

ORCID ID: https://orcid.org/0000-0003-1801-5828

$T$ ransposition of the great arteries (TGA) is a cyanotic congenital heart disease (CHD), accounting for approximately $5 \%$ of all cases. ${ }^{1}$ The incidence and prevalence of TGA are not well-documented in the Saudi population due to the lack of a unified data source. ${ }^{2}$ Transposition of the great arteries is characterized by ventriculoatrial discordance where the left ventricle is attached to the pulmonary artery, and the right ventricle is attached to the aorta. Transposition of the great arteries 
was not found to be associated with the most frequent syndromes, such as Turner, Noonan, Williams, Marfan, or Down syndromes. The only genetic syndrome that has a possible relation with TGA is heterotaxy. ${ }^{3}$ Patients with this disease can have a simple TGA, or it can be associated with other lesions (complex TGA), such as ventricular septal defect (VSD), left ventricle outflow tract (LVOT) obstruction, coarctation of the aorta, or any other possible association. It can also present as an association with other major $\mathrm{CHD}$, such as double outlet right ventricle and single ventricle. Transposition of the great arteries patients develop severe cyanosis shortly after birth, so prompt, adequate preoperative intervention and stabilization are needed. Without intervention, the majority of children born with TGA succumb to death in the neonatal period due to severe hypoxia. ${ }^{4}$ Those who survive the neonatal period will suffer from heart failure, arrhythmia, and death in the first year of life. The prognosis is excellent after surgical intervention, particularly in the modern era. Even though the detection rates of TGA by fetal echocardiography are inconsistent across different countries, mortality and morbidity were decreased when antenatally diagnosed. 5 Antenatal surveillance would allow for the timely transfer of infants born in remote hospitals to the tertiary health care centers to optimize surgical and neonatal care. This should eliminate shortfalls of diagnosing patients postnatally, and long-term sequelae, particularly the infants' neurodevelopment. There are international studies that have reviewed the risk factors for the development of TGA, but national data is still lacking in Saudi Arabia. ${ }^{6-8}$ This study aims to review the risk factors for the development of TGA in the Saudi population.

Methods. This was a retrospective case-control study on all children with TGA who were admitted to King Abdulaziz Cardiac Center, King Abdulaziz Medical City, Riyadh, Saudi Arabia. The study was approved by the Institutional Review Board at King Abdullah International Medical Research Center (KAIMRC). King Abdulaziz Cardiac Center is considered one of the largest tertiary care centers in Saudi Arabia. It provides advanced cardiac services to the whole population of the country, and it serves as one of the main referral centers. All children aged between one day and 18 years and

Disclosure. Authors have no conflict of interests, and the work was not supported or funded by any drug company. diagnosed with TGA between February 1999 and June 2016 were included in this study. Patients were divided into 2 groups: simple TGA with an intact ventricular septum and complex TGA with documented other cardiac anomalies, such as VSD, LVOT obstruction, and coarctation of the aorta. The exclusion criteria for the cases included single ventricle, congenitally corrected TGA (ccTGA), double outlet right ventricle, atrioventricular septal defect, or any TGA patient who was unavailable to reach.

Controls were healthy individuals without CHD, genetic disorder, or chromosomal anomalies. Controls were selected from the children seen at the outpatient clinics in King Abdullah Specialist Children Hospital. Randomly selected controls were age- and gendermatched with every TGA case. The random selection was on the basis of 2 controls for every case of TGA. Controls had no relation to the compared cases, but caution was taken to maintain similar ethnic and socioeconomic backgrounds.

A structured questionnaire was built to collect the variables of the study. The data were collected from the electronic hospital information system (BESTCare) for patient-related information including gender, age, type of TGA, type of surgery, age at surgery, other CHD, and antenatal diagnosis. All of the families of the cases and controls were interviewed by phone using a structured data sheet to collect information about paternal and maternal age, family history of CHD, maternal parity, presence of gestational diabetes, and consanguinity.

Consanguinity is described as a marriage between couples with one or more common ancestors, but we have included only the first cousin marriages in our variables. Fathers and mothers were classified into groups according to their age (under 25, 26-30, 31-35, 36-40, and above 41 years old). Maternal parity was classified into 1 to 2,3 to 4,5 to 6 , and above 7 . A family history of CHD was considered if the affected person is a first degree relative to the case or control. To study the magnitude of gestational diabetes, which is common in the Saudi population, we excluded mothers with pre-gestational diabetes from the analysis.

Statistical analysis. The data were analyzed using SPSS Statistics for Windows, Version 24.0 (Armonk, NY: IBM Corp.). Pearson's Chi-squared test was used to analyze and compare the distributions of categorical data in cases and controls. Fisher test was used when the sample size was small, and the Pearson Chi-squared test was not applicable. Logistic regression was used to evaluate the net effect of consanguinity, gestational diabetes, family history, parental ages, and parity on the overall risk of TGA. Results are reported as p-values 
and odds ratios with 95\% confidence interval (CI). A test with a $p$-value of less than 0.05 was considered statistically significant. Categorical data were presented as frequency and percentages, while numerical data were presented as mean and standard deviation.

Results. Between February 1999 and June 2016, 340 patients were admitted at King Abdulaziz Cardiac Center and diagnosed with transposition of the great arteries. Two hundred and six patients (57\%) were enrolled in the study while the rest of the patients (43\%) were excluded from the study due to syndromic heart defects $(3 \%)$ or unavailability of respondents (40\%). Hospital records identified 7 (1\%) out of 340 patients with TGA who died prior to surgery, and they were excluded. A total of 446 randomly selected controls with matching age and gender were included in the study. Of the studied cases, 130 (63\%) were males. Ninety-nine $(48 \%)$ of the cases were simple TGA, while 107 (52\%) were complex TGA. Consanguinity was found in 95 (46\%) of the studied cases, all of which were first cousins. Gestational diabetes was diagnosed in $36(17.5 \%)$ mothers. A family history of congenital heart disease was confirmed in first degree relatives in $35(17 \%)$ of the cases. The mean age of the father at birth was $37.5 \pm 9.2$ years, while $33 \pm 8$ years was the mean age for the mother at birth. The mean value for maternal parity was $5 \pm 2$ (Table 1 ).

To study the risk factors for developing TGA, we have compared the previous variables between the cases of TGA and the controls. Parental consanguinity was significantly associated with TGA $(\mathrm{OR}=$ 3.1; CI: 2.1-4.57, $p=0.001)$. Infants born to diabetic mothers had almost a 2-times increased risk of developing TGA at birth, compared to those born to non-diabetic mothers (OR=1.88; CI: 1.1-3.22, $p=0.022)$. Thirty-five $(17 \%)$ of the TGA cases have a positive family history of $\mathrm{CHD}$, while the positive

Table 1 - Distribution of risk factors between cases and controls.

\begin{tabular}{|c|c|c|c|c|}
\hline Variables & $\begin{array}{l}\text { TGA cases } \\
(\mathrm{n}=206) \\
\mathrm{n}(\%)\end{array}$ & $\begin{array}{c}\text { Controls } \\
\begin{array}{c}(\mathrm{n}=446) \\
\mathrm{n}(\%)\end{array}\end{array}$ & $\begin{array}{l}\text { Odds ratio } \\
(95 \% \text { confidence interval })\end{array}$ & $P$-value \\
\hline \multicolumn{5}{|l|}{ Gender } \\
\hline Male & $130(63.1)$ & $284(70.0)$ & 1.00 & 0.430 \\
\hline Female & $76(36.9)$ & $122(30.0)$ & $1.17(0.80-1.73)$ & \\
\hline \multicolumn{5}{|c|}{ Consanguinity } \\
\hline Positive & $95(46.1)$ & 81 & $3.1(2.1-4.57)$ & 0.001 \\
\hline Negative & $111(53.9)$ & $325(80.0)$ & 1.00 & \\
\hline \multicolumn{5}{|c|}{ Gestational diabetes } \\
\hline Yes & $36(17.5)$ & $37 \quad(9.1)$ & $1.88(1.1-3.22)$ & 0.022 \\
\hline No & $170(82.5)$ & $369(90.9)$ & 1.00 & \\
\hline \multicolumn{5}{|c|}{ Family history of CHDs } \\
\hline Positive & $35(17.0)$ & $24 \quad(5.9)$ & $2.81(1.55-5.11)$ & 0.001 \\
\hline Negative & $171(83.0)$ & $382(94.1)$ & 1.00 & \\
\hline \multicolumn{5}{|l|}{ Father age } \\
\hline$<25^{\circ}$ & $8 \quad(3.9)$ & $16 \quad(3.9)$ & 1.00 & 0.433 \\
\hline $26-30$ & $44(21.4)$ & 84 (20.7) & $1.12(0.41-3.06)$ & 0.832 \\
\hline $31-35$ & $48(23.3)$ & $103 \quad 25.4$ & $0.76(0.27-2.14)$ & 0.597 \\
\hline $36-40$ & $45(21.8)$ & $103(25.4)$ & $0.67(0.22-2.01)$ & 0.471 \\
\hline$>41$ & $61(29.6)$ & 100 (24.6) & $0.58(0.19-1.77)$ & 0.339 \\
\hline \multicolumn{5}{|l|}{ Mother age } \\
\hline$<25$ & $38(18.4)$ & $83(20.4)$ & 1.00 & 0.238 \\
\hline $26-30$ & $47(22.8)$ & $123(30.3)$ & $1.04(0.58-1.86)$ & 0.907 \\
\hline $31-35$ & $39(18.9)$ & $82(20.2)$ & $1.30(0.65-2.63)$ & 0.459 \\
\hline $36-40$ & $36(17.5)$ & $66(16.3)$ & $1.53(0.72-3.21)$ & 0.268 \\
\hline$>41$ & $46(22.3)$ & $52(12.8)$ & $2.28(1.04-4.97)$ & 0.038 \\
\hline \multicolumn{5}{|c|}{ Maternal parity } \\
\hline $1-2$ & $39(18.9)$ & $138 \quad(34.0)$ & 1.00 & 0.004 \\
\hline $3-4$ & $66(32.0)$ & $129 \quad(31.8)$ & $1.59(0.97-2.60)$ & 0.068 \\
\hline $5-6$ & $61(29.6)$ & $98 \quad(24.1)$ & $2.06(1.24-3.43)$ & 0.005 \\
\hline$>7$ & $40(19.4)$ & $41 \quad(10.1)$ & $2.88(1.56-5.34)$ & 0.001 \\
\hline
\end{tabular}


family history was present in $24(6 \%)$ of the control group (OR=2.81; CI: 1.55-5.11, $p=0.001)$. The risk of developing TGA was increased in infants born to mothers greater than 41 years old $(\mathrm{OR}=2.28$; $\mathrm{CI}$ : 1.04-4.97, $p=0.038$ ) while the father's age at birth was not found to be a risk factor for the development of TGA. Maternal parity was significantly associated with an increased risk of TGA. Higher parity was found to carry a higher risk of having an infant with TGA when compared to lower maternal parity. The overall risk of developing TGA was 2-times higher when the maternal parity was 5-6 compared to those with $1-2(\mathrm{OR}=2.06$; CI: 1.24-3.43, $p=0.005)$. The grand multipara status of the mother was found to carry the highest risk in those with parity of $\geq 7(\mathrm{OR}=2.88$; CI: $1.56-5.34, p=0.001)$. No association was found between TGA and the gender of the newborn (Table 1).
When studying the relation of the risk factors between simple and complex TGA, consanguinity was found to significantly increase the incidence and is thus regarded as a risk factor for the development of complex TGA. Consanguinity was positive in $61(57 \%)$ of the complex TGA cases while it was positive in 34 $(34 \%)$ of the patients with simple TGA $(\mathrm{OR}=2.42$; CI: 1.33-4.41, $p=0.004)$. Family history of CHD significantly increased the risk of complex type TGA $(\mathrm{OR}=2.40$; CI: 1.04-5.54, $p=0.041)$. Gestational diabetes, paternal age, and maternal parity were not found to be risk factors for the development of complex TGA (Table 2).

Half of the studied simple TGA patients were diagnosed in the first week of life, while the mean age at diagnosis was 2 weeks for the complex TGA patients $(p=0.002)$. The median age at surgery for simple TGA

Table 2 - Distribution of risk factors between the types of TGA (N=206).

\begin{tabular}{|c|c|c|c|c|c|c|}
\hline \multirow{2}{*}{$\begin{array}{l}\text { Variables } \\
\text { Gender }\end{array}$} & \multicolumn{2}{|c|}{$\begin{array}{c}\text { Simple TGA } \\
(\mathrm{n}=99) \\
\mathrm{n}(\%)\end{array}$} & \multicolumn{2}{|c|}{$\begin{array}{c}\text { Complex TGA } \\
\begin{array}{c}(\mathrm{n}=107) \\
\mathrm{n}(\%)\end{array}\end{array}$} & \multirow[t]{2}{*}{$\begin{array}{c}\text { Odds ratio } \\
(95 \% \text { confidence interval })\end{array}$} & \multirow[t]{2}{*}{$P$-value } \\
\hline & & & & & & \\
\hline Male & 65 & $(65.7)$ & 65 & $(60.7)$ & 1.00 & 0.371 \\
\hline Female & 34 & $(34.3)$ & 42 & (39.3) & $1.35(0.70-2.59)$ & \\
\hline \multicolumn{7}{|c|}{ Consanguinity } \\
\hline Positive & 34 & $(34.3)$ & 61 & $(57.0)$ & $2.46(1.35-4.48)$ & 0.003 \\
\hline Negative & 65 & $(65.7)$ & 46 & $(43.0)$ & 1.00 & \\
\hline \multicolumn{7}{|c|}{ Gestational diabetes } \\
\hline Yes & 17 & $(17.2)$ & 19 & $(22.4)$ & $0.91(0.41-2.02)$ & 0.833 \\
\hline No & 82 & $(82.8)$ & 88 & $(77.6)$ & 1.00 & \\
\hline \multicolumn{7}{|c|}{ Family history of CHDs } \\
\hline Positive & 10 & $(10.1)$ & 25 & $(23.4)$ & $2.49(1.08-5.73)$ & 0.032 \\
\hline Negative & 89 & $(89.9)$ & 82 & $(76.6)$ & 1.00 & \\
\hline \multicolumn{7}{|l|}{ Father age } \\
\hline$<25$ & 1 & $(1.0)$ & 7 & $(6.5)$ & 1.00 & 0.563 \\
\hline $26-30$ & 23 & $(23.2)$ & 21 & $(19.6)$ & $0.15(0.16-1.53)$ & 0.112 \\
\hline $31-35$ & 22 & $(22.2)$ & 26 & 24.3 & $0.19(0.19-1.98)$ & 0.166 \\
\hline $36-40$ & 22 & $(22.2)$ & 23 & $(21.5)$ & $0.18(0.01-2.04)$ & 0.170 \\
\hline$>41$ & 31 & $(31.3)$ & 30 & $(28.0)$ & $0.14(0.01-1.62)$ & 0.118 \\
\hline \multicolumn{7}{|l|}{ Mother age } \\
\hline$<25$ & 14 & $(14.1)$ & 24 & (22.4) & 1.00 & 0.798 \\
\hline $26-30$ & 27 & (27.3) & 20 & $(18.7)$ & $0.58(0.21-1.56)$ & 0.283 \\
\hline $31-35$ & 20 & $(20.2)$ & 19 & $(17.8)$ & $0.64(0.19-2.13)$ & 0.476 \\
\hline $36-40$ & 17 & $(17.2)$ & 19 & $(17.8)$ & $0.83(0.24-2.87)$ & 0.774 \\
\hline$>41$ & 21 & $(21.2)$ & 25 & $(23.4)$ & $0.89(0.25-3.12)$ & 0.865 \\
\hline \multicolumn{7}{|c|}{ Maternal parity } \\
\hline $1-2$ & 19 & (19.2) & 20 & $(18.7)$ & 1.00 & 0.808 \\
\hline $3-4$ & 32 & $(32.3)$ & 34 & $(31.8)$ & $0.77(0.32-1.86)$ & 0.567 \\
\hline $5-6$ & 31 & $(31.3)$ & 30 & $(28.0)$ & $1.02(0.43-2.42)$ & 0.959 \\
\hline$>7$ & 17 & $(17.2)$ & 23 & $(21.5)$ & $1.20(0.43-3.33)$ & 0.724 \\
\hline
\end{tabular}

TGA: transposition of the great arteries, CHD: congenital heart disease 
Table 3 - Distribution of age at diagnosis and at surgery between transposition of the great arteries (TGA) types.

\begin{tabular}{lcccccc}
\hline Variables/TGA type & Mean & SEM $^{*}$ & Median & Q1 & Q3 & $P$-value $^{\dagger}$ \\
\hline $\begin{array}{l}\text { Age at diagnosis } \\
\text { Simple }\end{array}$ & 83.19 & 32.11 & 6 & 2 & 16 & 0.002 \\
$\quad$ Complex & 69.61 & 15.05 & 14 & 5 & 55 & \\
$\begin{array}{l}\text { Age at surgery } \\
\text { Simple }\end{array}$ & 121.1 & 40.61 & 14 & 9 & 28 & $<0.001$ \\
Complex & 102.76 & 18.24 & 27 & 14 & 79 & \\
\hline \multicolumn{5}{c}{ *Standard error of mean, $\dagger$ p-value for Mann-whitney test was reported } \\
\hline
\end{tabular}

was 14 days, while it was 27 days for complex TGA $(p=0.001)$ (Table 3).

Discussion. Transposition of the great arteries is one of the most common cyanotic congenital heart defects. The aorta and pulmonary arteries are abnormally connected to the right and left ventricles. This produces a circulation incompatible with life, leading to hypoxia and death. Survival is highly dependent on the rapid diagnosis to intervene in a timely fashion, and if left untreated, the mortality may reach $97 \% .^{9}$ However, proper intervention within the first week of life reduces mortality and drastically improves the 20-year survival to $90 \%$ or more. ${ }^{10,11}$ Prenatal vigilant surveillance could be implemented for certain patient populations with known risk factors to lessen the burden of such disease. To our knowledge, this is the largest retrospective case-control study to investigate possible risk factors in patients diagnosed with TGA.

The association between consanguinity and congenital heart defects has been addressed in the literature, which has emphasized the possible role of consanguinity in increasing the risk of congenital heart disease. Nevertheless, none of the previous studies showed a significant association between consanguinity and TGA in particular. Our study demonstrates that consanguinity increases TGA's odds ratio by nearly 3-fold among the case group compared to the control group. The frequency of consanguinity in families with TGA was $46 \%$ compared to $20 \%$ in the control group with an OR of 3.1. In this study, first-degree consanguinity alone was investigated. Parents were considered as consanguineous if they were first degree cousins. Our study is the first to show a statistically significant association between first-cousin marriages and transposition of the great arteries. In contrast to our findings, Stavsky et al ${ }^{12}$ demonstrated that Bedouin's ethnicity, which is known to have high consanguineous marriages, had an odds ratio of 1.6 (CI: 0.99-2.52) to develop TGA, but this did not reach statistical significance. Nabulsi et $\mathrm{al}^{13}$ had similar results in which they did not find any significant association between consanguinity and TGA. Beker et $\mathrm{al}^{14}$ described that first cousin marriages are associated with certain defects, such as atrial septal defect (ASD), atrioventricular septal defect (AVSD), ventricular septal defect (VSD), pulmonary stenosis (PS), and pulmonary atresia (PA), but not TGA in the Saudi population. Similarly, Chehab et $\mathrm{al}^{15}$ found that patients with congenitally malformed hearts have higher consanguinity rates when compared to the control group. However, after subgroup analysis of each anomaly, patients with TGA did not have the same significant association.

On further investigation of the relation between consanguinity and the type of TGA, we detected an approximately 2 -fold increase in consanguinity in families with complex TGA (57\%) $(\mathrm{OR}=2.42$; CI: 1.33-4.41) compared to simple TGA (34\%). Previous literature did not investigate the role of consanguinity in complex TGA. However, other studies have been conducted on different complex cardiac lesions, such as double outlet right ventricle (DORV) and double inlet left ventricle (DILV). ${ }^{13,16}$ Gatrad et al $^{16}$ have studied D-TGA-like single ventricle defects, such as DORV and DILV, with pathophysiology and presentation similar to complex TGA. These authors revealed a significantly higher incidence of complex single ventricles lesions, such as DILV in Asian Muslims, with more consanguinity rates compared to English children $(p<0.001)$. In addition, Nabulsi et $\mathrm{al}^{13}$ showed a significant association between first-cousin marriage and the development of DORV in Lebanese patients $(p<0.05)$. Contrary to our findings, both studies revealed no significant association between TGA and parental consanguinity. A potential confounding factor for this discrepancy in the literature is the study population. Most of the current literature had been carried out with a relatively small number of TGA patients, while our study included a large 
population of 206 patients with TGA. Taken together with previous reports, this might indicate a possible genetic component as an autosomal recessive mode of inheritance resulting in the development of TGA. Consanguinity can be used to investigate the etiologies of diseases with an uncertain mode of inheritance as it promotes the homozygosity of genes. ${ }^{17}$ Our results expand the known association between consanguinity and CHD to include TGA in that association.

It is well noted that the Saudi population has a high rate of consanguineous marriages when compared to the western population. ${ }^{18}$ Our data showed that $46 \%$ of parents in the case group were first degree cousins. This was higher than what has been reported in a similar Saudi population (40\%), and greater than the national first-degree consanguinity rate (33.6\%). ${ }^{14,18}$ Regionally, first-degree marriage rates are lower than our figures in families with CHD. Chehab et al ${ }^{15}$ reported 19\% consanguinity in Lebanon, and Hamdan et $\mathrm{al}^{19}$ reported a rate of $44 \%$ in the United Arab Emirates. In light of these findings, efforts need to be made to enlighten parents with shared ancestors about the possible ramifications to their offspring, along with implementing prenatal screening programs for those with known consanguineous history to lessen TGA morbidity.

Gestational diabetes mellitus (GDM) is a known risk factor for some CHDs. In this study, we have investigated the risk of TGA in mothers who had gestational diabetes. We elected to avoid investigating the effect of pre-gestational diabetes. A nearly 2-fold increase in the risk of developing TGA was found in pregnancies complicated with gestational diabetes among the case group when compared to the control group. Increased perinatal morbidity and mortality were ascribed to gestational diabetes, along with the fact that pre-gestational diabetes is known to carry greater malformation risk. ${ }^{20-22}$ This significant association affirms the previously reported data linking diabetes to cardiovascular malformations. ${ }^{23-26}$ The effect of maternal insulin-dependent diabetes on the risk of developing cardiovascular malformation had been described. A meta-analysis found an increased likelihood of specific heart anomalies, such as TGA in infants born to diabetic mothers. ${ }^{23}$ Our data serves as emerging evidence that links TGA with gestational diabetes. It contradicts Mills et $\mathrm{al},{ }^{27}$ who reported no correlation between diabetes and a higher malformation rate. Stavsky et al ${ }^{12}$ stated that, unlike maternal diabetes, gestational diabetes in the case and control groups had a similar risk of CHD. Differently, the Baltimore Washington Infant Study
(BWIS) demonstrated the presence of a strong association between PDA and gestational diabetes, with a nearly 4-fold increased risk. ${ }^{28}$ Ramos et $\mathrm{a}^{29}$ had reported the possible link between GDM and TGA in which they found an OR of 22.1 (CI: 1.2-170.3), this association risk was significant, but the confidence interval is vastly wide. In contrast to that, our OR (1.88) was within a narrow confidence interval (CI: 1.1-3.22). Petropoulos et $\mathrm{al}^{30}$ concluded that the evidence sufficiently supports declaring pregnancies in mothers with gestational diabetes to have a similar risk to insulin-dependent diabetes mellitus in developing CHD, and to include them among the high-risk group needing fetal cardiac consultation. A possible cofounder that was overlooked is the association between pre-pregnancy BMI and the risk of CHD in offspring. Block et $\mathrm{al}^{31}$ found that TGA was affected by pre-pregnancy BMI $>30$ with an adjusted OR of 1.45 (CI: 1.16-1.80), and the risk slightly increased at higher BMI.

In our study, gestational diabetes among the case group was noted to reach $17.5 \%$. This figure is considered substantially higher than the global prevalence of GDM..$^{32}$ Badakhash et $\mathrm{al}^{33}$ stated in their meta-analysis that the Saudi population is among the highest recorded rates regionally, reaching up to $17.6 \%$, while the overall prevalence within East Mediterranean region reached $11.7 \%$. Of note, more recently, Alsaedi et $\mathrm{al}^{34}$ documented that GDM prevalence in the Saudi population reached $19.6 \%$, which is slightly higher than our figure.

The relationship between maternal age and GDM has been described in the literature. $\mathrm{Li}$ et $\mathrm{al}^{35}$ demonstrated that the risk of GDM linearly increases with successive age groups. The overall risk was 3.2 in mothers aged $30-34$ years compared to those aged 20-24 years. This risk continued to incrementally increase, and it reached 6.4 in those of 35-39 years old, and 9.6 in those greater than 40 years old. ${ }^{35}$ The mean maternal age in our study was 33 years, and this might contribute to further increase their risk to develop GDM, leading to higher CHD risk. The implications of these findings are versatile. Periodic antenatal ultrasound screening should be performed to better predict fetal complications and allow for timely intervention.

Maternal age has been linked in the literature with the risk of development of congenital malformation in the fetus. In our study, we found that advanced maternal age was associated with increased odds ratios when compared to the control group. Advancing maternal age showed an increasing trend toward giving birth to babies with TGA. There was a 2 -fold increased 
risk in mothers older than 41 years with an OR of 2.28 (CI: 1.04-4.97) and $p=0.038$. Previous studies have shown that maternal age above 35 years was noted to put infants at increased risk of CHD, while infants born to younger mothers had lower risk..$^{28,36-38}$ Stavsky et al ${ }^{12}$ found that conotruncal malformations, including TGA, were significantly associated with maternal age above 35 years. However, there is no unified consensus regarding this matter. ${ }^{39}$ Khalid et $\mathrm{al}^{40}$ indicated that there was no significant relationship between advanced maternal age and CHD. In their study on the Lebanese population, they stated that the effect of maternal age fades after the exclusion of chromosomal anomalies. Opposite to this observation, our population was free of chromosomal anomalies and shown to have this significant relation between the maternal age and TGA. Locally, Hashem et $\mathrm{al}^{41}$ reported an insignificant association between the overall CHD risk and mean maternal age, but when they did a sub-analysis for the sample, VSD and PDA were associated with maternal age $>35$ years, while the other lesions did not reach that significance. Their lack of significance was attributed to the low statistical power of their sample size.

The risk of paternal age varies in the international literature. Bassili et $\mathrm{a}^{42}$ found that paternal age greater than 40 years has a nearly 2 -fold increase in the risk of CHD. Opposite to that, our results showed a lack of association between paternal age and TGA. The likely explanation is the difference in the characteristics of the population and different genetic pools. In a different population in Sweden, neither paternal nor maternal age was found to have a significant association with a cardiac malformation in infants. ${ }^{43}$ The evidence supporting the relation of the advanced parental age and congenital heart anomalies at this point is inconsistent. Different degrees of associations were related to different populations across the world. Our study represents the Saudi population, and probably the regional populations.

Maternal parity carried a similar risk of TGA in our group. The risk increased 2-fold in mothers who had 5-6 parities, and this risk increased to nearly 3 -fold when the parity was more than $7(\mathrm{OR}=2.88$; CI: $1.58-5.41, p=0.001)$. Our results concur with the data from previous studies. ${ }^{12}$ The risk of congenital heart disease was described to increase by $6 \%$ per birth. ${ }^{25}$ Mothers with higher gravida had almost twice the risk compared to primigravida. ${ }^{8,40}$ Feng et $\mathrm{al}^{8}$ confirmed the effect of higher parity on congenital heart malformations, but could not stratify the risk of each subtype. Environmental influences might further explain the preceding results. Nutritional factors, such as folic acid, have been implicated in causing severe congenital anomalies, including CHD. ${ }^{44,45}$ Shorter inter-pregnancy interval in multiparous mothers, which might not allow storage levels to replenish adequately between pregnancies. ${ }^{45}$ Furthermore, psychological stressors during pregnancy had been reported to increase the risk of having children with CHD. ${ }^{46}$

A family history of cardiovascular malformation was found to be a significant predictor in our population, with a nearly 3 -fold increase in the risk among our case group $(\mathrm{OR}=2.81, \mathrm{CI}: 1.52-5.06, p=0.001)$. This further expands predictors of TGA among the Saudi population. An Egyptian epidemiological study reported that positive family history was found to be a significant risk factor, and the adjusted OR reached 8.5 within the first degree relatives and 6.5 within the second-degree relatives. ${ }^{42}$ Other epidemiological studies have indicated that family history positively predicted VSD, ASD, and PS. Also, our data is in accordance with the BWIS, where family history was found to increase the risk of congenital cardiovascular malformations. ${ }^{28}$

We have also found that positive family history of cardiovascular malformation increases the risk of complex TGA by 2 -fold when compared to simple TGA $(\mathrm{OR}=2.40 ; \quad \mathrm{CI}: 1.04-5.54, \quad p=0.041)$. This significant high rate of positive familial CHD history in complex TGA $(23.4 \%)$ indicates that complex TGA is more common in families with CHD history. An Italian multicenter study has analyzed familial congenital heart disease recurrence in families of both types of TGA (TGA with an intact ventricular septum and TGA with VSD) ${ }^{47}$ and found that recurrence of CHD was observed in $10 \%$ of TGA family relatives. ${ }^{47}$ However, no significant findings were reported in the familial recurrence between the 2 types of TGA. On the contrary, a significant difference in the history of familial CHD between simple and complex TGA was noted in our study population. This could be attributed to the fact that this study population had significantly higher rates of consanguinity, which predispose to the development of CHD.

In our study, the comparison between male and female gender with the type of TGA yielded a non-significant difference. However, there was a predominance of the male percentage in overall TGA $(63.1 \%)$. This is similar to other studies, where they noted a significantly higher prevalence in male patients affected by TGA. ${ }^{28,48}$ Likewise, results from Chehab et $\mathrm{al}^{15}$ showed a higher male ratio in discordant ventriculoatrial connections or DORV. This might indicate that complex TGA lesions 
can possibly be secondary to $\mathrm{X}$ chromosome gene mutations. A few molecular studies have investigated the presence of X-linked mutation inheritance in TGA. In support of that, Mégarbané et $\mathrm{al}^{49}$ explained, in part, the abundance of males in TGA when they identified a novel mutation in the ZIC3 gene that predisposes affected males to develop TGA.

The main limitation of this study is that it was performed at a tertiary care level.

In conclusion, our study revealed significant risk factors for the development of transposition of great arteries including first degree consanguineous marriages, gestational diabetes, family history of congenital cardiac anomalies, increasing maternal age and parity. Nearly all of the above-mentioned risk factors increased the chances by at least 2-fold. Our study is one of the largest case-control study to explore their significance in relation to TGA.

Further population-based study can be performed with higher numbers.

Acknowledgment. The authors gratefully acknowledge Dr. Talal Alharbi and Ms. Samar Merdad for their assistance during data collection.

\section{References}

1. Sarris GE, Balmer C, Bonou P, Comas JV, da Cruz E, Di Chiara $\mathrm{L}$, et al. Clinical guidelines for the management of patients with transposition of the great arteries with intact ventricular septum. Clinical guidelines for the management of patients with transposition of the great arteries with intact ventricular septum. Eur J Cardiothorac Surg 2017; 51: e1-e32.

2. Junghare SW, Desurkar V. Congenital heart diseases and anaesthesia. Indian J Anaesth 2017; 61: 744-752.

3. Al-Zahrani RS, Alharbi SH, Tuwaijri RMA, Alzomaili BT, Althubaiti A, Yelbuz TM. Transposition of the great arteries: A laterality defect in the group of heterotaxy syndromes or an outflow tract malformation? Ann Pediatr Cardiol 2018; 11 : 237-249.

4. Unolt M, Putotto C, Silvestri LM, Marino D, Scarabotti A, Massaccesi V, et al. Transposition of great arteries: New insights into the pathogenesis. Front Pediatr 2013; 1: 1-7.

5. Cloete E, Bloomfield FH, Sadler L, de Laat MWM, Finucane AK, Gentles TL. Antenatal detection of treatable critical congenital heart disease is associated with lower morbidity and mortality. J Pediatr 2019; 204: 66-70.

6. Shoukri MM, AlJufan M, Subhani S, Al-Mohanna F, Baig M, Al-Halees ZShoukri MM, et al. Consanguinity, maternal age, and maternal diabetes as potential risk factors for congenital heart diseases: A Nested Case Control Study from Saudi Arabia. J Epidemiol Public Heal Rev 2017; 2.2.

7. Luo YL, Cheng YL, Gao XH, Tan SQ, Li JM, Wang W, et al. Maternal age, parity and isolated birth defects: A populationbased case-control study in Shenzhen, China. PLoS One 2013; 8: 4-9.
8. Feng Y, Yu D, Chen T, Liu J, Tong X, Yang L, et al. Maternal parity and the risk of congenital heart defects in offspring: a dose-response meta-analysis of epidemiological observational studies. PLoS One 2014; 9: e108944.

9. Campbell M. Incidence of cardiac malformations at birth and later, and neonatal mortality. Br Heart J 1973; 35: 189-200.

10. Villafañe J, Lantin-Hermoso MR, Bhatt AB, Tweddell JS, Geva T, Nathan M, et al. D-transposition of the great arteries: The current era of the arterial switch operation. J Am Coll Cardiol 2014; 64: 498-511.

11. Khairy P, Clair M, Fernandes SM, Blume ED, Powell AJ, Newburger JW, et al. Cardiovascular outcomes after the arterial switch operation for D-transposition of the great arteries. Circulation 2013; 127: 331-339.

12. Stavsky M, Robinson R, Sade MY, Krymko H, Zalstein E, Ioffe $\mathrm{V}$, et al. Elevated birth prevalence of conotruncal heart defects in a population with high consanguinity rate. Cardiol Young 2017; 27: 109-116.

13. Nabulsi MM, Tamim H, Sabbagh M, Obeid MY, Yunis KA, Bitar FF. Parental consanguinity and congenital heart malformations in a developing country. Am J Med Genet A 2003; 116A: 342-347.

14. Becker S, Al-Halees Z, Molina C, Paterson R. Consanguinity and Congenital Heart Disease in Saudi Arabia. Am J Med Genet 2001; 99: 8-13.

15. Chehab G, Chedid P, Saliba Z, Bouvagnet P. Congenital cardiac disease and inbreeding: Specific defects escape higher risk due to parental consanguinity. Cardiol Young 2007; 17: 414-422.

16. Gatrad AR, Read AP, Watson GH. Consanguinity and complex cardiac anomalies with situs ambiguus. Arch Dis Child 1984; 59: 242-245.

17. Morton E. Empirical risks in consanguineous marriages: birth weight, gestation time, and measurements of infants. Am J Hum Genet 1958; 10: 344-349.

18. El-Mouzan M, Al-Salloum A, Al-Herbish A, Qurachi M, AA A-O. Regional variations in the prevalence of consanguinity in Saudi Arabia. Saudi Med J 2007; 1881-1884.

19. Hamdan MA, Chedid F, Bekdache GN, Begam M, Alsafi W, Sabri Z, et al. Perinatal outcome of congenital heart disease in a population with high consanguinity. J Perinat Med 2015; 43 : 735-740.

20. Gurleen K Sharland LEHGurleen K Sharland LEH. Maternal Gestational Diabetes and Fetal Congenital Heart Disease: An Observational Study. J Pregnancy Child Heal 2015; 2: 1-5.

21. Hornberger LK. Maternal diabetes and the fetal heart. Heart 2006; 92: 1019-1021.

22. Hadden DR, McLaughlin CHadden DR, McLaughlin C. Normal and abnormal maternal metabolism during pregnancy. Semin Fetal Neonatal Med 2009; 14: 66-71.

23. Lisowski LA, Verheijen PM, Copel JA, Kleinman CS, Wassink $\mathrm{S}$, Visser GHA, et al. Congenital heart disease in pregnancies complicated by maternal diabetes mellitus: An international clinical collaboration, literature review, and meta-analysis. Herz 2010; 35: 19-26.

24. Tabib A, Shirzad N, Sheikhbahaei S, Mohammadi S, Qorbani M, Haghpanah V, et al. Cardiac malformations in fetuses of gestational and pre gestational diabetic mothers. Iran J Pediatr 2013; 23: 664-668.

25. Nizard J, Ville YNizard J, Ville Y. The fetus of a diabetic mother: Sonographic evaluation. Semin Fetal Neonatal Med 2009; 14: 101-105. 
26. McMahon CL, Braddock SRMcMahon CL, Braddock SR. Maternal diabetes: An independent risk factor for major cardiovascular malformations with increased mortality of affected infants. Teratology 2001; 64: 98-106.

27. Hanson U, Persson B, Thunell SHanson U, Persson B, Thunell S. Relationship between haemoglobin A1c in early type 1 (insulin-dependent) diabetic pregnancy and the occurrence of spontaneous abortion and fetal malformation in Sweden. Diabetologia 1990; 33: 100-104.

28. Ferencz C, Loffredo C, Correa-Villasenor, Wilson P. Genetic and environmental risk factors of major cardiovascular malformations, The Baltimore-Washington Infant Study, (1981-1989), Perspectives in Pediatric Cardiology. Armonk (NY): Futur Publ Co. Inc.; 1998. p. 5.

29. Ramos-Arroyo MA, Rodriguez-Pinilla E, Cordero JF. Maternal diabetes: The risk for specific birth defects. Eur J Epidemiol 1992; 8: 503-508.

30. Seyidov NZ, Petropoulos A, Khudiyeva A, İsmailova İ. Congenital heart disease and maternal diabetes mellitus. Eurasian J Clin Sci 2018; 1: 32-39.

31. Block SR, Watkins SM, Salemi JL, Rutkowski R, Tanner JP, Correia JA, et al. Maternal pre-pregnancy body mass index and risk of selected birth defects: Evidence of a dose-response relationship. Paediatr Perinat Epidemiol 2013; 27: 521-531.

32. DeSisto CL, Kim SY, Sharma AJ. Prevalence estimates of gestational diabetes mellitus in the United States, pregnancy risk assessment monitoring system (PRAMS), 2007-2010. Prev Chronic Dis 2014; 11: 1-9.

33. Badakhsh M, Daneshi F, Abavisani M, Rafiemanesh H, Bouya S, Sheyback M, et al. Prevalence of gestational diabetes mellitus in Eastern Mediterranean region: a systematic review and metaanalysis. Endocrine 2019; 65: 505-514.

34. Alsaedi SA, Altalhi AA, Nabrawi MF, Aldainy AA, Wali RM. Prevalence and risk factors of gestational diabetes mellitus among pregnant patients visiting National Guard primary health care centers in Saudi Arabia. Saudi Med J 2020; 41: 144-150.

35. Li Y, Ren X, He L, Li J, Zhang S, Chen W. Maternal age and the risk of gestational diabetes mellitus: A systematic review and meta-analysis of over 120 million participants. Diabetes Res Clin Pract 2020; 162: 108044.

36. Miller A, Riehle-Colarusso T, Siffel C, Frías JL, Correa A. . Maternal age and prevalence of isolated congenital heart defects in an urban area of the United States. Am J Med Genet Part A 2011; 155: 2137-2145.

37. Reefhuis J, Honein MAReefhuis J, Honein MA. Maternal age and non-chromosomal birth defects, Atlanta - 1968-2000: Teenager or thirty-something, who is at risk? Birth Defects Res A Clin Mol Teratol 2004; 70: 572-579.
38. Rothman KJ, Fyler DCRothman KJ, Fyler DC. Sex, birth order, and maternal age characteristics of infants with congenital heart defects. Am J Epidemiol 1976; 104: 527-534.

39. Best KE, Rankin JBest KE, Rankin J. Is advanced maternal age a risk factor for congenital heart disease? Birth Defects Res Part A - Clin Mol Teratol 2016; 106: 461-467.

40. Yunis K, Mumtaz G, Bitar F, Chamseddine F, Kassar M, Rashkidi J, et al. Consanguineous marriage and congenital heart defects: A case-control study in the neonatal period. Am J Med Genet 2006; 140A: 1524-1530.

41. Hashim ST, Alamri RA, Bakraa R, Rawas R, Farahat F, Waggass $\mathrm{R}$. The association between maternal age and the prevalence of congenital heart disease in newborns from 2016 to 2018 in single cardiac center in Jeddah, Saudi Arabia. Cureus 2020; 12 : e7463.

42. Bassili A, Mokhtar SA, Dabous NI, Zaher SR, Mokhtar MM, Zaki A. Risk factors for congenital heart diseases in Alexandria, Egypt. Eur J Epidemiol 2000; 16: 805-814.

43. Cedergren MI, Selbing AJ, Källén BAJCedergren MI, Selbing AJ, Källén BAJ. Risk factors for cardiovascular malformation - A study based on prospectively collected data. Scand J Work Environ Heal 2002; 28: 12-17.

44. Rosenquist TH, Ratashak SA, Selhub J. Homocysteine induces congenital defects of the heart and neural tube: Effect of folic acid. Proc Natl Acad Sci U S A 1996; 93: 15227-15232.

45. Grisaru-Granovsky S, Gordon ES, Haklai Z, Samueloff A, Schimmel MMGrisaru-Granovsky S, Gordon ES, Haklai Z, Samueloff A, Schimmel MM. Effect of interpregnancy interval on adverse perinatal outcomes - a national study. Contraception 2009; 80: 512-518.

46. Feng Y, Yu D, Yang L, Da M, Wang Z, Lin Y, et al. Maternal lifestyle factors in pregnancy and congenital heart defects in offspring: review of the current evidence. Ital J Pediatr 2014; 40: 85.

47. Digilio MC, Casey B, Toscano A, Calabrò R, Pacileo G, Marasini M, et al. Complete transposition of the great arteries: Patterns of congenital heart disease in familial precurrence. Circulation 2001; 104: 2809-2814.

48. Bianca S, Ettore G. Sex ratio imbalance in transposition of the great arteries and possible agricultural environmental risk factors. Images Paediatr Cardiol 2001; 3: 10-14.

49. Mégarbané A, Salem N, Stephan E, Ashoush R, Lenoir D, Delague $\mathrm{V}$, et al. X-linked transposition of the great arteries and incomplete penetrance among males with a nonsense mutation in ZIC3. Eur J Hum Genet 2000; 8: 704-708. 